\title{
Traffic Congestion: Shift from Private Car to Public Transportation
}

\author{
Layth Riyadh Abdulrazzaq ${ }^{\text {a }}$, Mohammed Naeem Abdulkareem ${ }^{\mathrm{a}}$, \\ Muhamad Razuhanafi Mat Yazid ${ }^{\text {a* }}$, Muhamad Nazri Borhan ${ }^{a}$, Mina Salah Mahdi ${ }^{\text {a }}$ \\ ${ }^{a}$ Department of Civil Engineering, Faculty of Engineering \& Built Environment, Universiti Kebangsaan Malaysia, 43600 Bangi, Malaysia. \\ Received 17 April 2020; Accepted 03 July 2020
}

\begin{abstract}
Private Cars (PC) are becoming the most common way to travel daily. This is one of the effects of poor access to Public Transport (PT). As a result, increase air pollution, traffic congestion, noise, accidents. This study aims to develop a modal shift model for car users to shift to PT and determine the factors that effects the performance of the mode of transportation. A survey of 384 of PT users was conducted in Kajang city, Malaysia. Data were processed by SPSS software. A binary logit model has been used for three different lines (car, train and bus). The explanatory factors that looked at two models include trip distances, a trip rate per day, trip time, gender, age, and occupation, which are important variables. Mode Choice Model (Car vs Bus) show the travel time and distance travelled are significant factors to increase the use of public buses and reduce dependence on the car. While in Model (Car vs Train), the travel time is an important variable that effects of the switching decision between car and train. Younger people are more likely to switch in both models. Improve some factors like reliability in public transport services and change some fundamental policy could be the most effective measures for shifting from PC to PT.
\end{abstract}

Keywords: Traffic Congestion; Transport Policy; Mode Choice Model.

\section{Introduction}

The major challenge that roadway users faces every day in metropolitan cities is traffic congestion [1]. The rapid economic growth, employment and urban sprawl have led to increased numbers of commuters where the use of PC has spread over the past two decades; it has become one of the most common means of transport in Malaysia, this increase in cars leads to various traffic-related social problems [2]. Noise, pollution, global warming and impaired livability are just a few of the negative impacts of transportation systems around the world, these problems can largely be overcome by transforming car-centric cities into cities where PT and non-motorized transport are the dominant modes [3]. The increasingly active car uses in the cities in industrialized countries has led to increased accessibility problems of PC also cause transportation delays, accidents and emissions produced $[4,5]$.

Expanding the awareness of PT may reduce the quantity of accidents, decrease energy consumption, protect the environment and enhance the personal satisfaction [6]. Many factors play a key role to motivate PC users towards PT, the travel time and service system improvement are required to reduce PC dependency, park implementation with ride service facility near to the PT stations will enhance the PT users [7]. Reduce total travel time, travel cost and subsidized fares for the bus and train have directly effected on shifting [8,9]. Safety, reliability and cost is the most important criteria $(36 \%, 27 \% 21 \%$ of total) respectively for encouraging indicated the urban commuters to shift from private vehicles to PT , $96 \%$ of commuters want an efficient public transport system (PTS) for shifting [10]. There are

\footnotetext{
*Corresponding author: razuhanafi@ukm.edu.my
} 
some facilities like (seat availability, conditioning system, clean and comfortable bus and women bus service) can assist to encourage the switch to PT [11]. Environmental impact has some positive influences on the attitude to use PT [4]. The high quality of service is one of the best ways for pushing PC users and attracts them to PT, the important requirement to know how the PC users perceive briny attribute qualification up the quality of service being provided and which attributes they consider to be of greater, for more attractive the providers need to offer more accessible service $[12,13]$. Develop public transport connections and improve pedestrian walkway system by make the distance at least $500 \mathrm{~m}$ or $15 \mathrm{~min}$ walk to near station to attract more people to this sector [14].

In Malaysia, the traffic problems can be moderated, $45 \%$ reduction rate in travel time and cost will encourage more travelers to PT sector [15]. PC is the most common mode of transport, People not satisfied with current state of PT especially public bus, if this sector improved, they will use it instead of paying for tolls and outrageous petrol prices [16].

The area of this study is Kajang city; it is in the eastern part of Selangor, Malaysia. The total population of Kajang has grown rapidly in the last few years. PT sector in this city consist from two kind of train line (MRT and KTM) with two big stations for MRT, one station for KTM and network lines of buses, there is bus stop in each 1 kilometer at least. The traffic problems in this city should be alleviated by encouraging more commuters to use PT Through study the factors that influence car use and the potential to shift the drivers to the bus or train. This paper aims to develop a modal shift model for car users to shift to PT and the effectiveness of the transformation model in future transport use and determine the factors effecting on the performance of the mode of transportation. The Map in Figure 1 showing the area surveyed in Kajang around (plaza metro and metro point area).

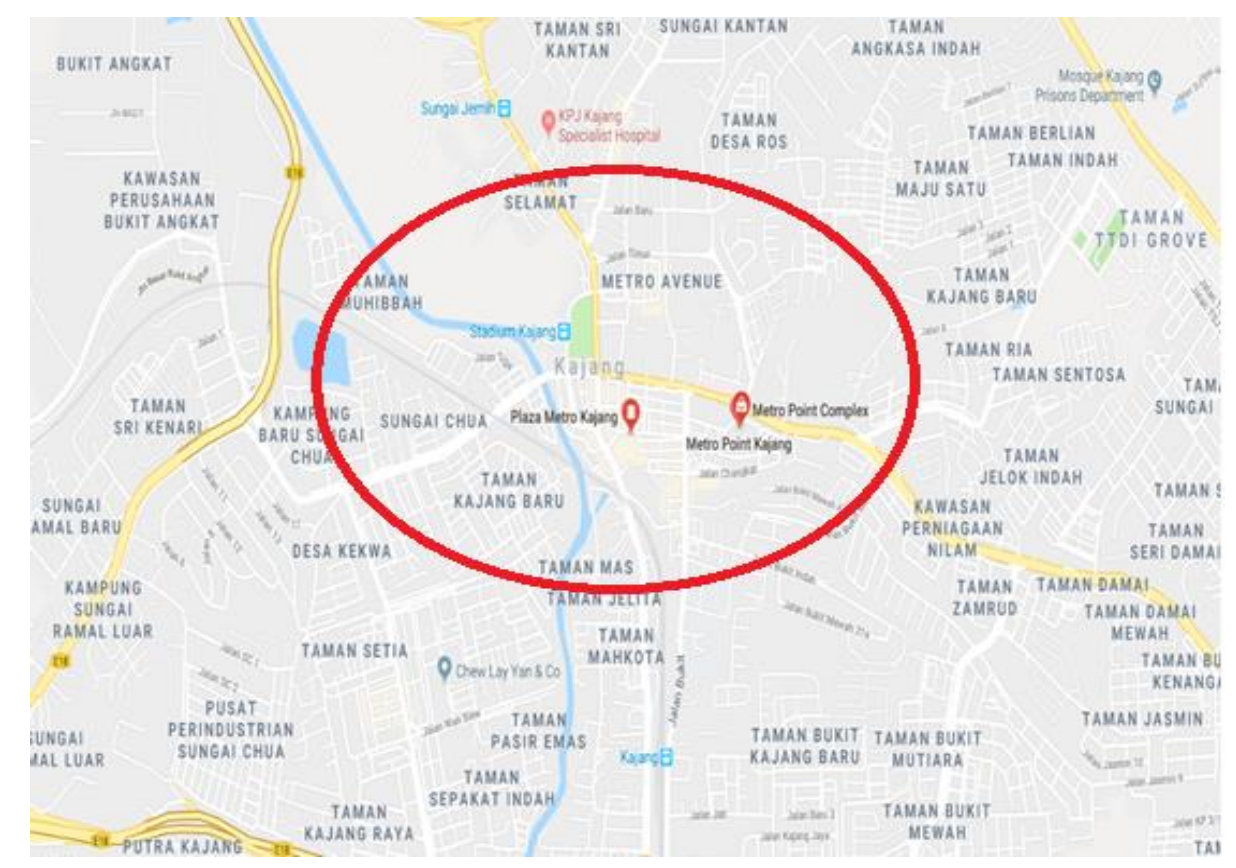

Figure 1. Area of study

\section{Methodology and Data Collection}

To reach the objective of this study, the survey was conducted in Kajang. To achieve a representative sample reflecting demographic, social, and economic characteristics, respondents were randomly selected on the basis of a stratified sampling approach. The data used for this study 384 real cases were randomly selected one and a half months. Determining the sample size is a very important issue because big samples may lose time, resources and money, while tiny samples may lead to false results. Therefore, selecting the sample size reduces the study risk whose results are not beneficial. The sample size was determined according to [17, 18].

A binary logit model is used as an analytically convenient modeling method. The first modal choice model (private car and public bus), the second model is the selection model (private car and public train) to identify the factors that will effect on car users to choose public transport and compare the utility of these means of travel. In this model, the dependent variable is " 1 " if the passengers of the public bus or the public train and "0" travel to use the vehicle.

The questionnaire information addressed for a car, bus and train users includes travel information of people, social and economic characteristics of people, perceptions, attitudes about travel and politics. Social and economic information includes age, gender, the range of income, vehicle ownership and family members, level of education and occupation. Trip information includes trip destination, travel time trip costs, trip distance, number of trips per week 
and per day. Regarding questions related to attitudes and preferences, respondents were asked to give an attitude view based on a list of traveler's perceptions about each travel feature. To illustrate the level of agreement with different statements, multiple options and scale scales have been used. The explanatory variables are gender, age, occupation, travel distance, travel time and trip rate per week. Data is processed using SPSS software version 24 to determine the relevant parts of the questionnaire that are not related to each other. Figure 2 shows the flow chart for this study.



Figure 2. Flow chart for illustration of strategies used for data collection and analysis

\section{Result and Discussion}

Depend on the survey in Kajang city, the most common factor that discourages to use public transport is the length of the public transportation journey, the percentage of the respondents who chose this factor is the highest at $39.1 \%$ while $26.2 \%$ said the public transport in the city not covered all the roads. $11.9 \%$ of people choose the infrequency public transport factor. While those who choose the unreliable service factor, too crowded factor, their percentage was $7.9 \%, 8.9 \%$ on respectively. And the percentage was $5 \%$ for those who choice factor uncomfortable, which means we must be improving these factors to attract these categories for public transport. Figure 3 show the knowledge of the public transport system (routes, fares and schedules) was good at average but need to improvement. 


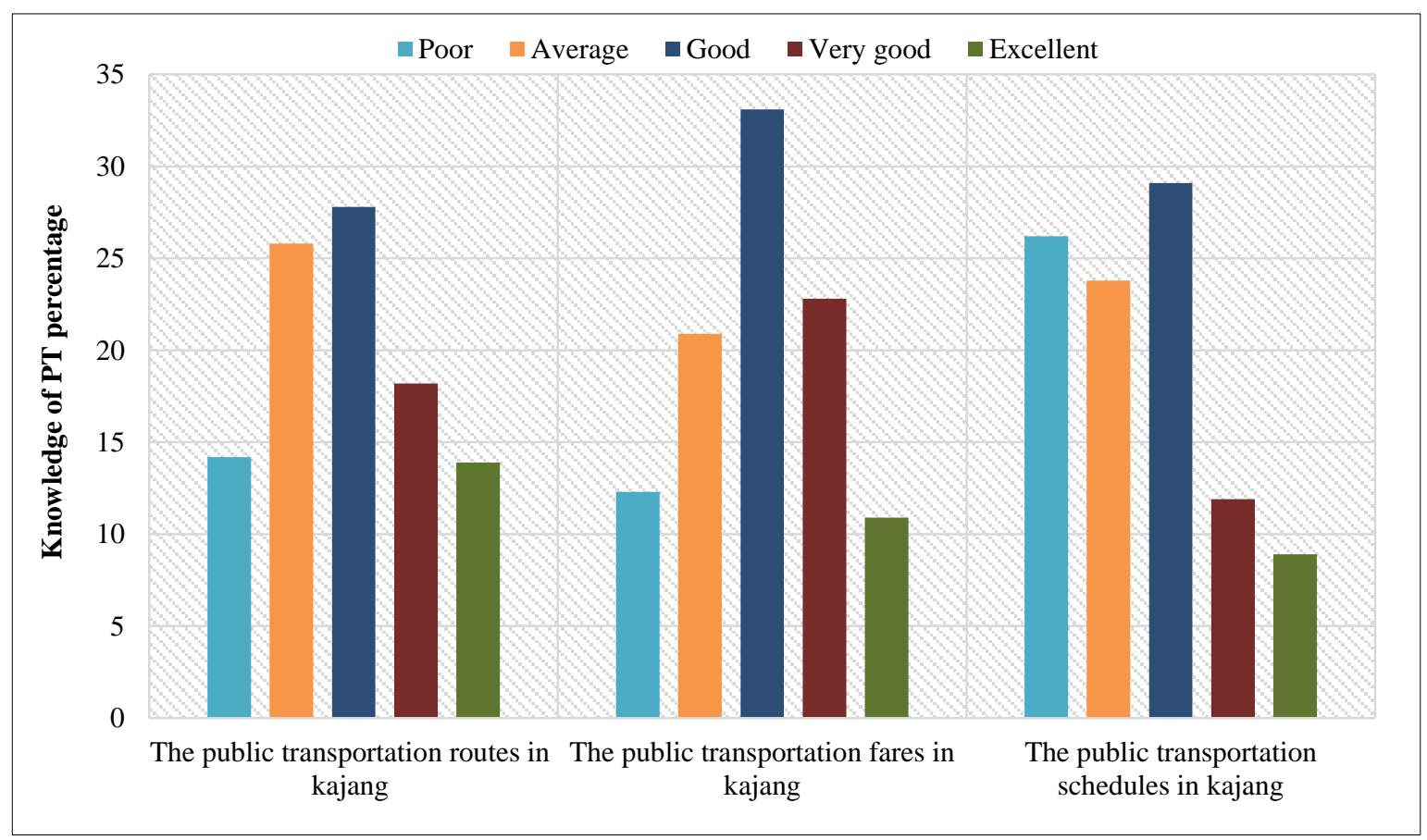

Figure 3. The knowledge about public transport percentage

Reduce travel time is one of the most important factors on the switch, $48.3 \%$ of people will shifting if the service is faster. While the percentage of a switch was $20.9 \%$ if we make the routes are more accessible. $16.9 \%$ if the service becomes more comfortable. While the percentage of the switch was $8.9 \%$ if we are reducing the fare and percentage of the switch was $5 \%$ if the public transport system becomes safer that means the public transport is very safe. Figure 4 shows the percentage of respondents according to the factor that makes them switch to public transport.

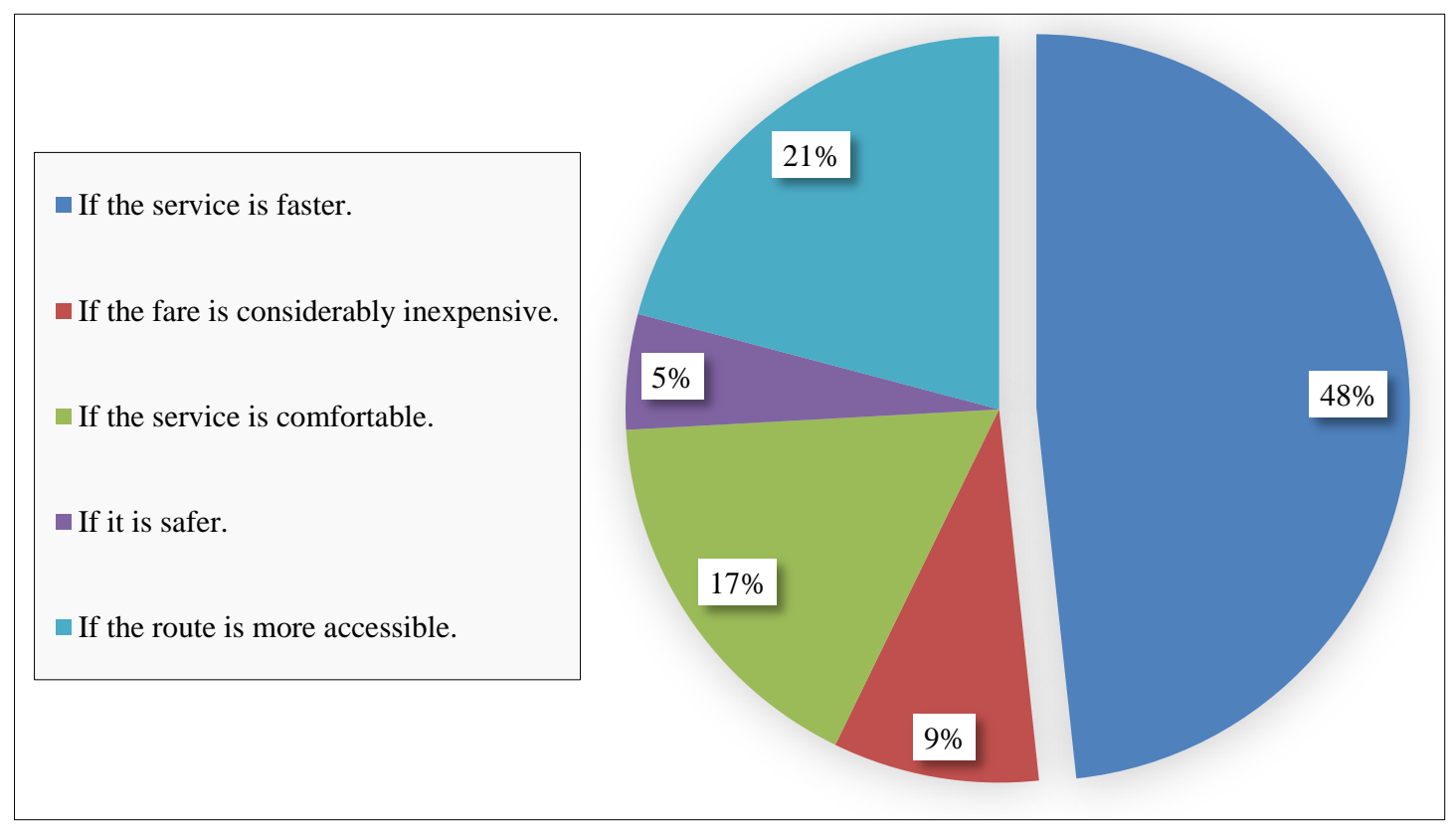

Figure 4. Common factors that help to switch to the PT

The shifting percentage from PC to the PT shown in Figure 5, if the travel time is reduced by $15 \%$, the percentage of the switch are $12.3 \%$, while those who consider that the amount of reduction is not enough to persuade them to switch, their percentage was $87.7 \%$. If the reduction was $30 \%, 28.1 \%$ will shift but $71.9 \%$ still refused the switch. If the travel time reduced to $45 \%$, the switching percentage $62.3 \%$, while $37.7 \%$ still refused the switch and if reduced to $60 \%$, the switching percentage is the highest at $100 \%$. 


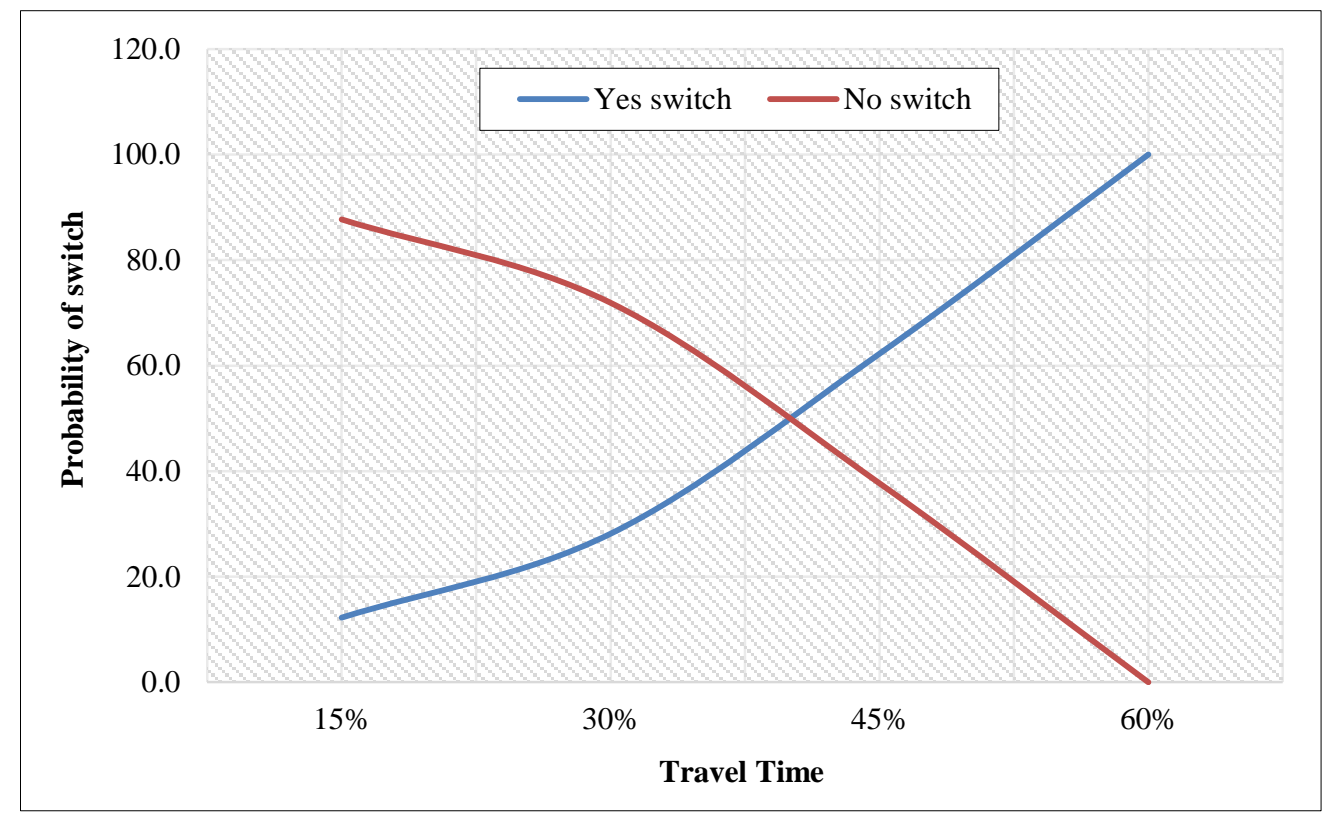

Figure 5. Percentages of switch and not switch from PC to PT according to travel time

If public transport travel cost reduced to $15 \%$, the percentage of users who will shifting are $7.9 \%$, while those who consider that the amount of reduction in travel cost is not enough to persuade them to switch to PT their percentage was $92.1 \%$. While if the reduction is $30 \%, 28.8 \%$ will switch but $71.2 \%$ still refused. If the travel cost reduced to $45 \%$, the switching percentage $54.3 \%$, while $45.7 \%$ still refused the switch. The switching percentage is the highest at $100 \%$, if the cost reduced to $60 \%$ as shown in Figure 6 . There are many factors have effect on shifting like Schedule accuracy (59.9\%), Fare is low (14.9\%), Vehicles are not too crowded (13.9\%), Vehicles are clean and Free trip time $(12.9 \%)$ on users of private car to make them switch to public transport. the best qualities encourage to switch to the PT is the schedules accuracy.

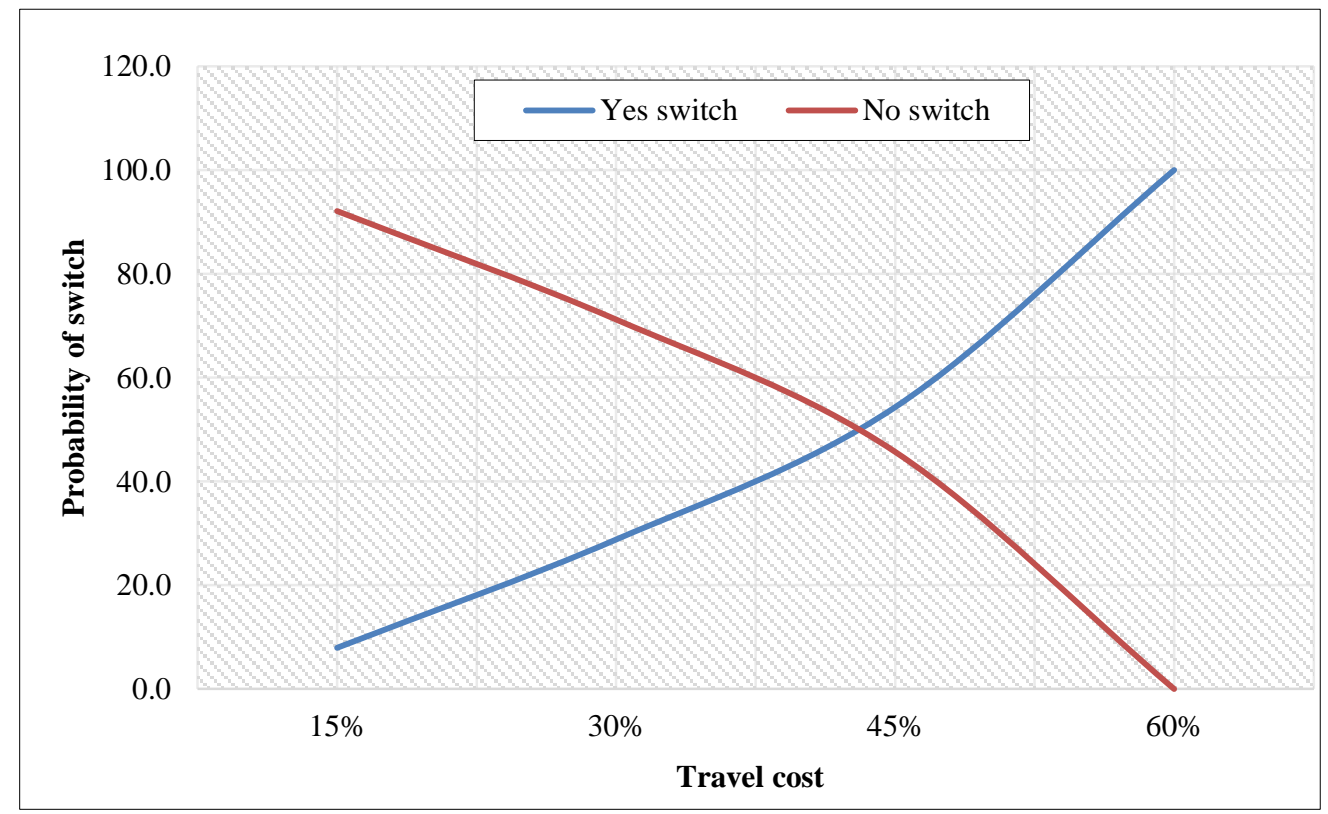

Figure 6. Percentages of switch and not switch from PC to PT according to travel cost

\subsection{Mode Choice Model Car vs. Bus}

A binary logit model has been used for switching from cars to public buses. All the variables shown in the Table 1 contain logical signs and significant parameter estimates. A trip rate per day, Travel time, age, gender, trip distance and occupation are important variables to represents the important contribution of the variable to model prediction. The result shown the males prefer to switch from car to the public bus instead of driving, the odds ratio increased by approximately $48.9 \%$ for males compared to females, while the odds ratio increases about $30 \%$ for young people 
compared with the older commuters that's mean younger people are more likely to use the bus instead the car. The estimated duration of the trip proved positive and concluded that even when the trip time was increased, passengers were likely to keep their decision on a switch to the public bus. Reduces the likelihood that car users will continue to choose the vehicle as the preferred mode of transport. The trip distance coefficient is negative, which means that the increase in this variable may increase the vehicle's use even though it ( $p>0.05)$ significantly effects of the switching decision. The explanatory force of the model, R-Square values refers to the strong explanatory force of the model. The factors involved in the calculation model are $41.3 \%$ of the variance for Negelkerke, while Cox and Snell can explain $20.1 \%$.

Table 1. Estimation from the binary mode choice model (car vs. bus)

\begin{tabular}{|c|c|c|c|c|c|c|}
\hline & \multirow{2}{*}{ B } & \multirow{2}{*}{ S.E. } & \multirow{2}{*}{ Sig. } & \multirow{2}{*}{ Odds ratio } & \multicolumn{2}{|c|}{ 95\% C.I. } \\
\hline & & & & & Lower & Upper \\
\hline Gender & -0.715 & 0.416 & 0.085 & 0.489 & 0.217 & 1.104 \\
\hline Occupation & 0.570 & 0.220 & 0.010 & 1.768 & 1.148 & 2.722 \\
\hline Trip rate per day & 0.192 & 0.142 & 0.178 & 1.211 & 0.917 & 1.601 \\
\hline Distance travelled & -2.262 & 0.384 & 0.000 & 0.104 & 0.049 & 0.221 \\
\hline Travel time in min & 0.967 & 0.258 & 0.000 & 2.630 & 1.586 & 4.363 \\
\hline Age & -1.204 & 0.335 & 0.000 & 0.300 & 0.156 & 0.578 \\
\hline Constant & 2.043 & 1.192 & 0.086 & 7.711 & & \\
\hline \multicolumn{7}{|l|}{ Summary of statistics } \\
\hline$-2 \mathrm{LL}$ & & & & 170.33 & & \\
\hline Model Chi-square & & & & 86.30 & & \\
\hline Cox and Snell's R ${ }^{2}$ & & & & 0.201 & & \\
\hline Nagelkerke Value & & & & 0.413 & & \\
\hline Number of observations & & & & 384 & & \\
\hline
\end{tabular}

\subsection{Mode Choice Model Car vs. Train}

To explain the effects of the variables for switching from private car to public train, a binary logistic regression has been implemented. Table 2 shown the estimated factors for daily trip rate, trip distance, gender, age, travel time, and registered function as major contributors at $95 \%$ confidence level $(\mathrm{p}<0.05)$ to media selection behavior. The result shows the estimated coefficients of gender for the train mode is positive, the odds ratio increased by approximately $76.8 \%$ for males compared to females that are mean the male prefer to use train instead of driving the car. The estimated coefficients for trip distance and travel time for train were positive that's mean the commuters prefer the switch even the trip distance and trip time were increased. The coefficient for the trip rate per day for train is negative that's mean an increase in commuters trip rate would decrease the train users. The explanatory force of the model, RSquare values refers to the strong explanatory force of the model. The factors involved in the calculation model are $20 \%$ of the variance for Negelkerke, while Cox and Snell can interpret $10 \%$.

Table 2. Estimation from the binary mode choice model (car vs. train)

\begin{tabular}{|c|c|c|c|c|c|c|}
\hline & \multirow{2}{*}{ B } & \multirow{2}{*}{ S.E. } & \multirow{2}{*}{ Sig. } & \multirow{2}{*}{ Odds ratio } & \multicolumn{2}{|c|}{ 95\% C.I. } \\
\hline & & & & & Lower & Upper \\
\hline Gender & -0.264 & 0.372 & 0.477 & 0.768 & 0.370 & 1.592 \\
\hline Occupation & 0.066 & 0.166 & 0.688 & 1.069 & 0.772 & 1.479 \\
\hline Trip rate per day & -0.054 & 0.129 & 0.676 & 0.947 & 0.735 & 1.221 \\
\hline Distance travelled & 0.462 & 0.250 & 0.064 & 1.587 & 0.973 & 2.588 \\
\hline Travel time in min & 0.501 & 0.191 & 0.009 & 1.651 & 1.134 & 2.402 \\
\hline Age & -0.224 & 0.217 & 0.302 & 0.799 & 0.522 & 1.223 \\
\hline Constant & -4.881 & 1.107 & 0.000 & 0.008 & & \\
\hline \multicolumn{7}{|l|}{ Summary of statistics } \\
\hline$-2 \mathrm{LL}$ & & & & 223.97 & & \\
\hline Model Chi-square & & & & 41.15 & & \\
\hline Cox and Snell's R² & & & & 0.10 & & \\
\hline Nagelkerke Value & & & & 0.20 & & \\
\hline Number of observations & & & & 384 & & \\
\hline
\end{tabular}


Chi-square test for Tables 1 and 2 was performed between observed and predicted frequencies. It should also be noted that we have assigned the dependent variable to "1" if the passenger is traveling by public bus or public train and "0" to use the vehicle. The chi-square was significant for model 1, there was a slight difference between observed and predicted values for car and bus that's mean the good fit of the mode. For model 2 there was slight difference between observed and predicted values for car and train while the chi-square was not significant. Table 3 shows the results of a case classification of logistic regression models. The best model should determine a higher proportion of cases correctly. According to the model, the evaluation matrices assess whether the model is appropriate for the data and show that the model correctly classifies about $97.4 \%$ of car cases and about $22.5 \%$ of bus, while the overall accuracy of the prediction for model 2 was $89.1 \%$, as shown in Table 4.

Table 3. Classification of mode choice (car vs. bus)

\begin{tabular}{cccc}
\hline Observed & \multicolumn{3}{c}{ Predicted } \\
\hline & \multicolumn{2}{c}{ Mode choice } & Percentage \\
& Car & Bus & Correct \\
\hline Car & 335 & 9 & 97.4 \\
Bus & 31 & 9 & 22.5 \\
Overall Percentage & & & 89.6 \\
\hline
\end{tabular}

Table 4. Classification of mode choice (car vs. train)

\begin{tabular}{cccc}
\hline Observed & \multicolumn{3}{c}{ Predicted } \\
\hline & \multicolumn{2}{c}{ Mode choice } & Percentage \\
\cline { 2 - 3 } & Car & Train & Correct \\
\hline Car & 339 & 3 & 99.1 \\
Train & 39 & 3 & 7.1 \\
Overall Percentage & & & 89.1 \\
\hline
\end{tabular}

\section{Conclusion}

Traffic congestion can be reduced by drawing travelers away from PC over to PT. Unique data set was collected to study the travel behaviour contribute, a survey with a sample size of 384 done in Kajang city. Two models were developed by SPSS software to study people choice method. The reasons behind the insistence on the use of PC as well as the factors are effecting on the use of PT and the impact of these factors in the switching to public transport were compared. In model 1 , the Travel time and distance travelled are the most important issues by solving twodimensional logistic models for the potential use of many travel features to increase the use of buses and reduce dependence on the car. While in Model 2, travel time is a significant factor that determines the choice of taking the train or using car and the increase in trip rate would decrease their train use. We believe that our findings have somehow completed the results of Almselati et al. (2015) study [15], which have analyzed the travel time and parking cost in same city based on spike model. The result also in line with Anwar et al. (2017) research [7]. Service improvement (more frequent, more refined trips) and parking fees increasing will be reduced the congestion on the roads that contribute to reduce pollution and increased safety. Changing the age of the driver's license will be a good idea as well to ensure the use of PT because it's found that the most people who use cars in this city are young. Promoting a sustainable community and Educational campaigns to spread awareness among the public of PT. Provide Wi-Fi in all PT lines and charge battery, establish a professional application have schedule with real time information for each line especially bus networks by connect it with GPS system, special discount in peak hours especially for young people, develop announcing speakers in stop station exactly in bus and KTM, MRT have a good speaker's system. All this suggestion is a good way to attract people to switch to the train, bus instead of private car.

\section{Funding and Acknowledgements}

The authors would like to thank The Ministry of Higher Education Malaysia and National University of Malaysia for their financial support under the grant Fundamental Research Grant Scheme FRGS/1/2019/TK08/UKM/02/1.

\section{Conflicts of Interest}

The authors declare no conflict of interest. 


\section{References}

[1] Small, Kenneth A. “The Economics of Urban Transportation” (October 18, 2007). doi:10.4324/9780203642306.

[2] Chiu Chuen, Onn, Mohamed Rehan Karim, and Sumiani Yusoff. "Mode Choice between Private and Public Transport in Klang Valley, Malaysia.” The Scientific World Journal 2014 (2014): 1-14. doi:10.1155/2014/394587

[3] Hitge, Gerhard, and Marianne Vanderschuren. "Comparison of travel time between private car and public transport in Cape Town." Journal of the South African Institution of Civil Engineering 57, no. 3 (2015): 35-43. doi:10.17159/23098775/2015/v57n3a5.

[4] Borhan, Muhamad Nazri, Deprizon Syamsunur, Norliza Mohd Akhir, Muhamad Razuhanafi Mat Yazid, Amiruddin Ismail, and Riza Atiq Rahmat. "Predicting the Use of Public Transportation: A Case Study from Putrajaya, Malaysia." The Scientific World Journal 2014 (2014): 1-9. doi:10.1155/2014/784145.

[5] Buehler, Ralph, and John Pucher. "Walking and cycling in Western Europe and the United States: trends, policies, and lessons." Tr News 280 (2012).

[6] Din, Mokhtar Azizi Mohd, Saritha Paramasivam, Nazirah Md Tarmizi, and Abd Manan Samad. "The Use of Geographical Information System in the Assessment of Level of Service of Transit Systems in Kuala Lumpur." Procedia - Social and Behavioral Sciences 222 (June 2016): 816-826. doi:10.1016/j.sbspro.2016.05.181.

[7] Anwar, A.H.M. Mehbub, and Jie Yang. "Examining the Effects of Transport Policy on Modal Shift from Private Car to Public Bus.” Procedia Engineering 180 (2017): 1413-1422. doi:10.1016/j.proeng.2017.04.304.

[8] Mohammed, Ali Ahmed. "An Optimization Solution for Utilization Minibuses Service as an Alternative of Utilize Private Cars: A Case Study Around Hentian Kajang in Malaysia.” IOSR Journal of Engineering 02, no. 05 (May 2012): $1032-1039$. doi:10.9790/3021-020510321039.

[9] Yuniar, Dewi, Ludfi Djakfar, Achmad Wicaksono, and Achmad Efendi. "Truck Driver Behavior and Travel Time Effectiveness Using Smart GPS.” Civil Engineering Journal 6, no. 4 (April 1, 2020): 724-732. doi:10.28991/cej-2020-03091504.

[10] Jain, Suresh, Preeti Aggarwal, Prashant Kumar, Shaleen Singhal, and Prateek Sharma. "Identifying Public Preferences Using Multi-Criteria Decision Making for Assessing the Shift of Urban Commuters from Private to Public Transport: A Case Study of Delhi." Transportation Research Part F: Traffic Psychology and Behaviour 24 (May 2014): 60-70. doi:10.1016/j.trf.2014.03.007.

[11] Anik, Md Asif Hasan, Fuad Ahmed, Fahmun Nabi Atin, Nuzhat Tabassum Ahmed, Amit Mutsuddy, Musaddik Al Imran, Nazia Haque, Tasman Zihan, and Rafiz Rayhan. "Motivating Factors for Private Car Users to Use Public Transport." International Journal for Traffic and Transport Engineering 8, no. 1 (2018). doi:10.7708/ijtte.2018.8(1).06.

[12] De Oña, Juan, Esperanza Estévez, and Rocío de Oña. "Perception of Public Transport Quality of Service among Regular Private Vehicle Users in Madrid, Spain.” Transportation Research Record: Journal of the Transportation Research Board 2674, no. 2 (February 2020): 213-224. doi:10.1177/0361198120907095.

[13] Saif, Muhammad Atiullah, Mohammad Maghrour Zefreh, and Adam Torok. "Public Transport Accessibility: A Literature Review." Periodica Polytechnica Transportation Engineering 47, no. 1 (May 3, 2018): 36-43. doi:10.3311/pptr.12072.

[14] Noor, Khairul Baharein Mohd, and Kamariah Dola. "Towards Low Carbon Society: Exploring Users' Perceptions on the Service Quality Level Performance of Public Transport Staff in the Klang Valley." International Journal of Management and Sustainability 2, no. 8 (2013): 138-149.

[15] Almselati, Aldukali Salem I., Riza Atiq bin O.K. Rahmat, Othman Jaafar, and Hussin A.M. Yahia. "Using Spike Model to Reduce Traffic Congestion and Improve Public Transportation in Malaysia.” Transportation Research Part D: Transport and Environment 38 (July 2015): 59-66. doi:10.1016/j.trd.2015.04.005.

[16] Kamba, Abdalla Nurdeen, Riza Atiq O.K. Rahmat, and Amiruddin Ismail. "Why Do People Use Their Cars: A Case Study in Malaysia.” Journal of Social Sciences 3, no. 3 (March 1, 2007): 117-122. doi:10.3844/jssp.2007.117.122.

[17] Krejcie, Robert V., and Daryle W. Morgan. "Determining Sample Size for Research Activities." Educational and Psychological Measurement 30, no. 3 (September 1970): 607-610. doi:10.1177/001316447003000308.

[18] Muhamad Razuhanafi Mat Yazid \& Mohd Azizu Ladim. "Urban Design and Active-Transport." International Journal of Engineering and Advanced Technology (IJEAT) ISSN: 2249 - 8958, Volume-4 Issue-3 (2015):132-135. 